\title{
Vaporizer Device
}

National Cancer Institute

\section{Source}

National Cancer Institute. Vaporizer Device. NCI Thesaurus. Code C50262.

A device designed to convert a solution to an aerosol or mist, especially one to prepare a medication for inhaling. 